\title{
PELAKU UMKM MUSLIM MADURA DALAM MENGHADAPI ERA BISNIS DIGITAL: ANALISIS PELUANG DAN ANCAMAN
}

\author{
Mohammad Hamim Sultoni \\ Fakultas Ekonomi dan Bisnis IAIN Madura \\ hamimsultoni@iainmadura.ac.id \\ Ah. Shibghatullah Mujaddidi \\ Fakultas Ekonomi dan Bisnis IAIN Madura \\ Ira Hasti Priyadi \\ Fakultas Ekonomi dan Bisnis IAIN Madura
}

Masuk : 11-12-2021, revisi : 13-02-2021 diterima untuk diterbitkan : 15-02-2021

\begin{abstract}
The era of industry 4.0 increases the use of digital platforms to improve business performance, covering marketing, operational, and financial management needs. SMEs as part of business actors are required to be able to adapt to the digital business era. This study aimed to analyze the SMEs in Madura in facing the changes from the traditional to the digital business era and to explore the perspectives of the opportunities and threats they face. A total of 10 MSME actors from various fields who are indigenous Madurese became interviewees in this study. The results showed that $74 \%$ of the sample had made adjustments and implemented digital platforms for their business development.
\end{abstract}

Abstrak: Era industry 4.0 membuat penggunakan platform digital dalam meningkatkan performa bisnis menjadi pesat, baik itu untuk kebutuhan pemasaran, operasional hingga pengelolaan keuangan. UMKM sebagai bagian dari pelaku usaha dituntut untuk mampu beradaptasi menghadapi era bisnis digital. Penelitian ini bertujuan untuk menganalisa para UMKM Madura dalam menghadapi perubahan era bisnis tradisional kearah digital serta menggali perspektif peluang dan ancaman yang mereka hadapi. Sebanyak 10 pelaku UMKM dari berbagai bidang yang merupakan masyarakat asli Madura menjadi narasumber wawancara dalam penelitian ini. Hasil penelitian menunjukkan bahwa $74 \%$ sampel telah melakukan penyesuaian dan menggunakan platform digital untuk pengembangan bisnis mereka.

Keywords: Small Medium Entreprise, Madurese Society, Digital Business

\section{PENDAHULUAN}

Usaha Mikro Kecil dan Menengah sangat berperan dlam memberikan sumbangsih pekembangan dan pertumbuhan neraca ekonomi suatu negara. Beberapa masalah seperti mengurangi pengangguran dan meningkatkan barang ekspor merupakan masalah yang dapat diselesaikan dengan menggalakkan semangat UMKM. (Yamani et al., 2019). Sumbangsih UMKM dapat dilihat salah satunya melalui rasio Produk Domestik Bruto (PDB). (Suprayitno, 2018). PDB merupakan nilai tambah yang diperoleh dari perhitungan seluruh unit usaha dalam suatu negara atau perhitungan jumlah nilai barang dan jasa hasil dari segala bentuk unit produktifitas ekonomi pada negara tersebut. UMKM di Indonesia memiliki kontribusi PDB Nasional pada tahun 2014 sebesar 5.40\%, mengalami peningkatan pada tahun 2015 sebesar 6.46\% dan pada tahun 2016 menjadi 6.86\% berdasarkan Badan Pusat Statistik menurut harga berlaku.

Undang-undang Nomor 20 tahun 2008 tentang Usaha Mikro, Kecil dan Menengah (UMKM) mengatur tentang pelaksanaan Usaha Mikro, Kecil dan Menengah (Hartono \& 
Hartomo, 2016). Beberapa istilah dan karakteristik UMKM dapat dijelaskan sebagai berikut: (1) Usaha Mikro, yaitu usaha yang dimiliki perorangan atau badan usaha yang dimiliki oleh individu/perorangan. (2) Usaha Kecil, yaitu usaha bergerak dibidang ekonomi dengan tujuan produktifitas baik dikelola sendiri maupun dikelola melalui badan usaha akan tetapi bukan termasuk anak perusahaan dan juga bagian dari anak cabang perusahaan. Sedangkan, (3) Usaha Menengah merupakan bagian usaha ekonomi dengan tujuan produktifitas yang berdiri sendiri, baik dikelola secara perorangan maupun melalui badan usaha yang bukan termasuk bagian anak perusahaan atau cabang perusahaan yang dikuasai dan dimiliki, serta menjadi bagian secara langsung maupun tidak langsung dengan jenis usaha kecil maupun besar.

Sejarah UMKM pada tahun 1997 dalam menghadapi krisis, UMKM telah mampu dan terbukti menjaga kestabilan siklus usahanya.(Sudayanto, Ragimun, dan Rahma, 2011) Pada saat 1997, krisis ekonomi telah banyak mempenagruhi silklus usaha yang berskala besar. Bahkan, stagnasi turut dialami oleh beberapa usaha yang berskala besar, Namun, kestabilan UMKM dalam menjaga keberlangsungan usaha membuktikan ketangguhan dalam menghadapi krisis tersebut. Badan Pusat Statistik menyebutkan data bahwa pada tahun 1997-1998 menunjukkan bahwa UMKM dapat bertahan terhadap serangan krisis. Pembukaan lapangan kerja mengakibatkan peningkatan penyerapan tenaga kerja yakni perusahaan kecil 57,40 juta $(87,62 \%)$, perusahaan sedang 7,7 juta $(11,75 \%)$ dan perusahaan besar 0,393 juta $(0,61 \%)$. Sedangkan pada 1998 menunjukkan perusahaan kecil 57,34 juta (88,66\%), perusahaan sedang 6,9 juta $(10,78 \%)$ dan perusahaan besar 0,364 juta $(0,56 \%)$.

\section{TELAAH KEPUSTAKAAN}

Era digital atau yang biasa disebut Digitalisasi, sedikit banyak telah mengubah ekosistem bisnis dan ritel serta sistem pada tempat usaha atau toko konvensional. Begiut pula pada Media yang kini banyak menjadi pilihan dalam bisnis juga dapat dikatakan sebagai platform online yang dapat digunakan seseorang dengan tujuan berbagi dan berinteraksi seperti berbagi konten. Dalam hal ini termasuk situs media sosial, portal berita online, serta situs jejaring geososial, blog, forum komunikasi online, file sharing, games/permainan, dan bisnis. Perkembangan Internet dan ekonomi serta peningkatan interaksi sosial melalui media, sosial budaya telah mendorong bisnis untuk memanfaatkan infrastruktur dan fasilitas lokal serta memasuki pasar luar negeri melalui strategi digital (transaksional) (Sousa \& Rocha, 2019).

Kondisi pada era industri 4.0 mengharuskan para pelaku UMKM menghadapi tantangan sekaligus peluang kedepan. Era Industri 4.0 mengharuskan Pelaku UMKM untuk beradaptasi dan melakukan disrupsi bisnis ke era digital atau disebut digitalisasi bisnis (Slamet et al., 2017). Era globalisasi menuntut peningkatan inovasi produk dan jasa, pengembangan skill dari sumber daya manusia, pengembangan teknologi dan perluasan area pemasaran. Selain itu, kondisi ini juga menuntuk perbaikan dan peningkatan tingkat pendidikan, keahlian (keterampilan) pekerja, dan penggunaan modal usaha relatif sedikit serta teknologi yang digunakan.

Pada penelitian yang dilakukan oleh Amin dan Dwi dengan judul Pengembangan Usaha Mikro Kecil dan Menengah (UMKM) Berbasis Industri Kreatif di kota Malang, menghasilkan data perkembangan UMKM di kota Malang berbasis industri kreatif dengan melihat kekuatan, kelemahan, ancaman dan peluang di sektor kuliner, kerajinan, fashion, musik, dan permainan interaktif, serta untuk menentukan strategi dan strategi utama untuk pengembangan UMKM berbasis industri kreatif di sektor kuliner, kerajinan, fashion, musik, dan permainan interaktif di Kota Malang. Kota Malang sudah memiliki banyak potensi di 15 sektor industri kreatif, dari semua sektor tersebut tiap sektor memiliki kekuatan, kelemahan, peluang dan ancaman yang berbeda. Selain itu, banyak permasalahan di tiap sektor seperti permasalahan Sumber Daya Manusia (SDM) seperti pada sektor kuliner, kerajinan, fashion, dan permainan interaktif (Ananda \& Susilowati, 2019). 
Pulau madura memiliki empat kabupaten yaitu Bangkalan, Sampang, Pamekasan dan Sumenep dengan jumlah yang diperkirakan begitu banyak juga di dukung dengan kepadatan sekitar $706 \mathrm{~km}$ (Nugraha \& Murniawaty, 2018). Masyarakat Madura memiliki etos berwirausaha yang kuat. Ciri khas semangat dan kegigihan dalam berbisnis membuat masyarakat Madura memiliki pondasi budaya dan nilai utama dalam membangun perekonomian daerah melalui eksistensi UMKM. Dari banyaknya jumlah rumah tangga yang tersebar di empat kabupaten di madura ini menjadi salah satu potensi untuk membuat lapangan kerja disektor UMKM (Usaha Mikro, Kecil dan Menengah). Adapun yang menjadi fokus kajian ini adalah membahas mengenai peluang dan ancaman dari Usaha Mikro Kecil Menengah (UMKM) di Madura

\section{METODOLOGI PENELITIAN}

Penelitian ini dikerjakan dengan kerangka penelitian lapangan (field research) yaitu penelitian megeksplorasi secara intensif tentang latar belakang keadaan sekarang, dan interaksi suatu sosial, individu, kelompok, lembaga, dan masyarakat (Bungin, 2011). Data primer penelitian dikumpulkan melalui observasi dan wawancara. Peneliti melakukan wawancara dilakukan kepada 10 pelaku UMKM Muslim Madura dari empat bidang usaha yaitu : produk, jasa, ekonomi kreatif dan industri rumah tangga.. Validitas data diuji dengan menggunakan metode konfirmasi antara hasil penelitian lapangan, studi pustaka dan beberapa kajian penelitian terdahulu. Berikut adalah rincian pemetaan responden dalam penelitian ini :

\section{Tabel 1}

\section{Daftar Responden}

\begin{tabular}{|l|l|l|c|}
\hline No & Jenis Usaha & Bidang Usaha & Jumlah \\
\hline 1 & Produk & $\begin{array}{l}- \text { Kuliner } \\
- \text { Toko Bahan Bangunan }\end{array}$ & 2 \\
\hline 2. & Jasa & $\begin{array}{l}\text { - Cuci Kendaraan } \\
- \text { Pangkas Rambut } \\
- \text { Laundry }\end{array}$ & 3 \\
\hline 3. & Ekonomi Kreatif & $\begin{array}{l}- \text { Batik Tulis } \\
- \text { Keramik }\end{array}$ & 2 \\
\hline 4. & Industri Rumah Tangga & $\begin{array}{l}- \text { Kerupuk } \\
- \text { Tempe } \\
- \text { Tahu }\end{array}$ & 3 \\
\hline
\end{tabular}

\section{ANALISA DAN PEMBAHASAN}

\section{Kajian Dampak Era Bisnis Digital bagi UMKM}

Besarnya jumlah penduduk Indonesia yang mencapai sekitar 255 juta jiwa, serta kian meningkatnya penetrasi penggunaan internet dan pesatnya dunia bisnis digital. Berdasarkan Survey Asosiasi Penyelenggara Jasa Internet Indonesia (APJII) Penetrasi internet telah melebihi 35 persen tahun 2016 dan melebihi 50\% pada tahun 2017 di atas batas minimum penetrasi 30 persen yang menjadi acuan perusahaan internet kelas dunia untuk melakukan penetrasi ke suatu negara Teknologi pun kini menjadi salah satu motor ekonomi Indonesia karena memudahkan orang untuk memulai usaha di mana pun. Berdasarkan pemaparan diatas dapat disimpulkan bahwa teknologi merupakan peluang pelaku usaha UMKM dapat berbisnis dengan mudah dan murah (Chowdhury, 2015).

Potensi industri sejenis berbasis online di Indonesia masih sangat besar dan setiap tahun terus meningkat. E-commerce, tidak semata membicarakan jual beli barang dan jasa via internet. Tetapi ada industri lain yang terhubung di dalamnya. Seperti penyediaan jasa layanan antar atau logistik, provider telekomunikasi, produsen perangkat pintar, dan lain-lain. Hal inilah yang membuat industri ini harus dikawal dengan cepat, termasuk dari aspek regulasinya agar mampu mendorong laju perekonomian nasional, Kekuatan jaringan infrastruktur terus berupaya merpertajam industri jasa layanan berbasis teknologi informasi, e-commerce, serta logistics system dengan mengandalkan kekuatan teknologi digital. Ke depan potensi e- 
commerce bakal makin besar, apalagi tren belanja online juga terus meningkat dan bisa diakses dari mana saja (Devi et al., 2020).

Terdapat dua belas karakteristik penting yang diperkenalkan dalam ekonomi digital yang harus dipahami oleh para wirausahawan. Dua belas karakteristik tersebut adalah: (1) knowledge; (2) digitalizion; (3) virtualization; (4) molecularization; (5) internetworking; (6) disintermediation; (7) convergence; (8) innovation; (9) presumption; (10) immediacy; (11) globalization; (12) discordance (Kasidi, 2020).

\section{Peluang dan Ancaman UMKM Madura di Era Bisnis Digital}

Opportunities (peluang) dan Threats (ancaman) merupakan bagian eksternal dalam Analisis SWOT yang mempengaruhi bisnis atau hal-hal yang terjadi di luar perusahaan Anda pada pasar yang lebih besar. Berikut ini adalah ulasan hasil penelitian lapangan mengenai Peluang dan Ancaman UMKM Madura:

Tabel 2

Peluang dan Ancaman UMKM Muslim Madura

\begin{tabular}{|c|c|c|}
\hline Responden & Peluang & Ancaman \\
\hline - Kuliner & $\begin{array}{l}\text { Diversifikasi produk dalam jenis } \\
\text { frozen food atau Inovasi makanan } \\
\text { tahan lama agar dapat dibeli secara } \\
\text { online }\end{array}$ & $\begin{array}{l}\text { Munculnya makanan sejenis yang } \\
\text { memiliki daya tahan lebih lama }\end{array}$ \\
\hline - Toko Bahan Bangunan & $\begin{array}{l}\text { Mengadakan layanan antar jarak } \\
\text { jauh, menciptakan aplikasi katalog } \\
\text { online. }\end{array}$ & $\begin{array}{l}\text { Telat dalam inovasi dan konsumen } \\
\text { beralih kepada layanan bahan } \\
\text { bangunan yang lebih mudah aksesnya }\end{array}$ \\
\hline - Cuci Kendaraan & Membuka layanan cuci panggilan & $\begin{array}{l}\text { Pelaku usaha tidak cepat beradaptasi } \\
\text { dan konsumen mulai beralih kebiasaan } \\
\text { mencuci kendaraan sendiri }\end{array}$ \\
\hline - Pangkas Rambut & $\begin{array}{l}\text { Membuka layanan potong rambut } \\
\text { panggilan. } \\
\text { engagement konsumen melalui } \\
\text { social media }\end{array}$ & $\begin{array}{l}\text { Konsumen memiliki referensi model } \\
\text { potongan rambut yang tidak bisa } \\
\text { dipenuhi oleh UMKM sekitar }\end{array}$ \\
\hline - Laundry & Layanan antar jemput cucian. & Muncul Aplikasi Laundry online \\
\hline - Batik Tulis & $\begin{array}{l}\text { Memperluas pangsa pasar dan } \\
\text { supplier melalui marketplace }\end{array}$ & $\begin{array}{l}\text { Adanya pesaing penjual baju batik jadi } \\
\text { dalam social media }\end{array}$ \\
\hline - Keramik & $\begin{array}{l}\text { Memperluas pangsa pasar dan } \\
\text { supplier melalui marketplace }\end{array}$ & $\begin{array}{l}\text { Muncul pesaing baru yang menyajikan } \\
\text { pilihan katalog dan ekspedisi yang } \\
\text { dapat diakses secara online }\end{array}$ \\
\hline - Kerupuk & $\begin{array}{l}\text { Memperluas pangsa pasar dan } \\
\text { supplier melalui marketplace }\end{array}$ & $\begin{array}{l}\text { Muncul pesaing bisnis menjual olahan } \\
\text { kerupuk aneka rasa dengan kemasan } \\
\text { lebih baik dan dijual secara online }\end{array}$ \\
\hline - Tempe & $\begin{array}{l}\text { Memperluas pangsa pasar dan } \\
\text { supplier melalui marketplace }\end{array}$ & Masih minim \\
\hline - Tahu & $\begin{array}{l}\text { Memperluas pangsa pasar dan } \\
\text { supplier melalui marketplace }\end{array}$ & Masih minim \\
\hline
\end{tabular}

\section{KESIMPULAN DAN SARAN}

Era bisnis digital bisa menjadi peluang sekaligus ancaman bagi Usaha Mikro, Kecil, dan Menengah (UMKM) di Madura. Setidaknya ada duabelas karakteristik UMKM yang dapat dipersiapkan dalam menghadapi industry ekonomi kreatif yaitu (1) knowledge; (2) digitalizion; (3) virtualization; (4) molecularization; (5) internetworking; (6) disintermediation; (7) convergence; (8) innovation; (9) presumption; (10) immediacy; (11) globalization; (12) discordance. Dari hasil penelitian menunjukkan bahkan 10 UMKM yang menjadi responden dalam penelitian ini memiliki tinjauan peluang dan ancaman yang berbeda dan secara umum $74 \%$ telah siap menghadapi era industry digital.

Secara umum peluang bagi UMKM Muslim Madura diantaranya: 1) Memperluas cakukan pasar dan pemasok melalui marketplace, 2) Mengembangkan layanan berbasis digital, 
3) Memaksimalkan interconnecting konsumen dalam social media dan gadget terhadap pemasaran dan optimalisasi memperkenalkan jenis usaha. Adapun dari segi ancaman adalah 1) Munculnya pesaing baru yang lebih siap dan adaptasi terhadap bisnis digital, 2) Perubahan perilaku konsumen yang beralih ke jenis bisnis yang memberikan akses layanan lebih mudah, murah dan berkualitas, 3) Inovasi dan diversifikasi produk terhambat karena minimnya pengetahuan pelaku usaha.

\section{DAFTAR PUSTAKA}

Ananda, A. D., \& Susilowati, D. (2019). Pengembangan usaha mikro kecil dan menengah (UMKM) berbasis industri kreatif di kota Malang. Jurnal Ilmu Ekonomi, 10(10), 120142.

Bungin, B. (2011). Penelitian kualitatif: Komunikasi, ekonomi, kebijakan publik, dan ilmu sosial lainnya. In Kencana.

Chowdhury, M. M. (2015). Small and Medium Enterprise in Bangladesh-Prospects and Small and Medium Enterprise in Bangladesh Prospects and Challenges. January.

Devi, C., Rusma, M., Mikro, U., \& Lambalek, A. (2020). Sosialisasi Digital Marketing pada Usaha Mikro Kecil Menengah (UMKM), 2(1), 63-73.

Hartono, H., \& Hartomo, D. D. (2016). Faktor-faktor yang mempengaruhi perkembangan UMKM di Surakarta. Jurnal Bisnis dan Manajemen, 14(1), 15. https://doi.org/10.20961/jbm.v14i1.2678

Kasidi. (2020). Tantangan Kewirausahaan di Era Ekonomi Digital. 1(1), 1-7. https://doi.org/https://doi.org/10.31331/ekonomi.vlil.kode artikel

Maryati, W., Masriani, I., Studi, P., Bisnis, A., Manajemen, P. S., \& Jambi, U. (2019). Peluang Bisnis di Era Digital Bagi Generasi Muda dalam Berwirausaha. 4, 53-58.

Nugraha, A. E. P., \& Murniawaty, I. (2018). Sharia digital business: Strategi dan pengembangan bisnis berkelanjutan. Equilibrium: Jurnal Ekonomi Syariah, 6(2), 241. https://doi.org/10.21043/equilibrium.v6i2.3623

Paul, P. K., Bhuimali, A., Tiwary, K., Aithal, P. S., \& Rajesh, R. (2018). Digital business towards an academic and professional degree: An international perspective. International Journal on Recent Researches in Science, Engineering \& Technology (IJRRSET), 6(5), 1-10. https://doi.org/10.5281/zenodo.1292852

Sedyastuti, K. (2018). Analisis pemberdayaan UMKM dan peningkatan daya saing dalam kancah pasar global. INOBIS: Jurnal Inovasi Bisnis dan Manajemen Indonesia, 2(1), 117-127. https://doi.org/10.31842/jurnal-inobis.v2i1.65

Slamet, R., Nainggolan, B., Roessobiyatno, R., Ramdani, H., Hendriyanto, A., \& Ilma, L. L. (2017). Strategi pengembangan UKM digital dalam menghadapi era pasar bebas. Jurnal Manajemen Indonesia, 16(2), 136. https://doi.org/10.25124/jmi.v16i2.319

Sousa, M. J., \& Rocha, Á. (2019). Skills for disruptive digital business. Journal of Business Research, 94(August 2017), 257-263. https://doi.org/10.1016/j.jbusres.2017.12.051

Sudayanto, Ragimun, \& Rahma, R. (2011). Strategi pemberdayaan UMKM menghadapi pasar bebas ASEAN. Universitas Negeri Jember, 1(1). http://jurnal.unpad.ac.id/sosiohumaniora/article/view/12249/6227

Sugiyono. (2016). Memahami Penelitian Kualitatif. Bandung: Alfabeta.

Suprayitno, D. K. (2018). Pemberdayaan usaha mikro kecil dan menengah (UMKM) di Kabupaten Sidoarjo. Program Studi Ilmu Administrasi Negara, FISIP, Universitas Airlangga, 1-13.

Yamani, A. Z., Muhammad, A. W., \& Faiz, M. N. (2019). penguatan ekonomi lokal pada pelaku UMKM berbasis digital di Desa Winduaji Kabupaten Brebes. Madani: Indonesian Journal of Civil Society, 1(1), 24-28. https://doi.org/10.35970/madani.v1i1.29 